\section{Talk of science and philosophy}

\section{Donald MacKay}

The Philosophy of Popper.

By T.E. Burke.

Manchester University Press: 1983.

Pp.220. £6.50, $\$ 8$.

IN a year that has seen the publication (at last) of Sir Karl Popper's famous threevolume Postscript (see Nature 300, $663-664,1982 ; 302,357-358,1983)$, there would be little need for yet another summary of his philosophical position. What Dr Burke has provided (despite his textbookish title) is something quite different. Recognizing that "his own works are by far the best sources of information about the context of [Popper's] thought" (p.vii) he has chosen instead to take some of Popper's key ideas as a starting point for critical enquiries which explore much wider territory. In the process he brings out both the strengths and the weaknesses he sees in Popper's massive contribution to contemporary thinking about the nature of science and scientific reasoning, of human society and human freedom, and indeed of the philosophical enterprise itself.

The book falls into five sections, concerned respectively with the philosophy of philosophy, the philosophy of science, relativism and truth, historicism, and freedom and values. In each, Popper's characteristic emphases are noted, with the help of representative quotations; but on the whole the reader is expected to be familiar with their original context, and to be interested mainly in the way they relate to other strands of contemporary thought.

Popper sees philosophy as a critical or mind-clearing response to crises that arise (typically) in other fields of interest. As such it has genuine problems to tackle; and Popper had no time for the Wittgensteinian idea that its goal should be to dissolve rather than solve them. But what Burke asks is whether, after all, Popper and Wittgenstein had as much to quarrel over as they thought; and he argues that Popper's own philosophizing "can equally well be presented as almost classical examples of Wittgensteinian philosophy". Popper's famous refutation of historicism, for example, "hinges on the claim that, given a sufficiently careful description of the relevant disciplines, and drawing of the demarcation-lines between them, the temptations of historicist programmes disappear"' (p.25).

For Popper our main concern, whether as scientists or philosophers, is, or ought to be, the search for truth; no mere instrumentalism could do justice to the drive behind the scientific enterprise. Yet paradoxically he is also famous for the doctrine that though science is seeking truth, it can never have logically sufficient grounds for claiming to have found it. Induction, in particular, he has dismissed as "a myth". Burke, while sympathetic to Popper's reasons for such radical scepticism, argues that "his taste for the dramatic has led him to overstate his case" (p.48). Burke insists that for any serious attack on falsehood or ignorance, we need a basis of established truths, however limited, which can and must be secured in ways that avoid the corrosion of universal scepticism. Without this, he argues, Popper's uncompromising rejection of relativism runs into logical difficulties.

What Popper rejected, of course, was not the principle of relativity as such, but the tendency, especially among social scientists, to turn it into a denial of objectivity. "By relativism", he said, "I mean the theory that the choice between competing theories is arbitrary" (cited on p.82).

Popper's terminology does not make it as clear as he might that a thorough-going relativist can also be a thorough-going objectivist, provided that there are objective transformations linking statements that are valid from different standpoints. Burke, however, goes further and maintains that "there is a case for rela-

\section{Planning ahead}

\section{Warren R. Jones}

\section{Birth Control Technologies: Prospects by} the Year 2000.

By Michael J.K. Harper.

Heinemann Medical/University of Texas

Press: 1983. Pp.270. £15, \$27.50.

THIS timely and comprehensive volume highlights the salient question surrounding global activities in fertility regulation. The social and personal imperatives for effective family planning are as pressing now as they have ever been, but the strategic priorities remain unclear - whether to concentrate finite resources on improving the distribution and acceptability of existing contraceptive methods, or to promote further research into new technologies.

Contraception research and development has now reached a watershed. In recent years, partly as a result of the economic recession, there has been a relative decline in the funding of goalorientated research into reproduction. This decline began at a time when at least some new contraceptive techniques had reached a critical stage of development. Further progress will now only be made either by dint of serendipitous breakthrough or by more investment of high-risk capital by international agencies and pharmaceutical companies.

The book is built around Dr Harper's critical perception of the current state of the contraceptive art and of prospects for the practical application of new and tivism in the form in which Popper denounces it" '(p.86); but the case he makes is not particularly strong.

Scientific theories can indeed be surprisingly resilient in face of contradictory evidence; but this does nothing to justify Feyerabend's claim (cited on p.70) that "we can turn science from a stern and demanding mistress into an attractive and yielding courtesan who tries to anticipate every wish of her lover"'. It does, however, as Burke points out, tend to soften the sharp epistemic contrast usually drawn by Popperian fallibilists between scientific and metaphysical doctrines.

These examples typify Burke's treatment of his theme - respectful and sympathetic, but refreshingly independent, and eager to report what he can see when standing on the shoulders of his chosen giant. $\mathrm{He}$ handles language with a craftsman's skill and precision, and though seldom humorous is never dull. Reading him will be a stimulating experience for anyone who, having absorbed Popper's eloquent message, wonders what remains to be said.

Donald MacKay is Emeritus Professor of Communication and Neuroscience at the University of Keele.

improved birth control technologies by the year 2000. Each method - current, new and potential - is comprehensively reviewed and supported by an up-to-date and extensive, though critical, survey of relevant literature. The author's predictions are grouped in temporal categories of implementation: highly likely before 1990; possible, but prospects doubtful by 1990; unlikely before 1990 but possible by 2000 . Most promise is seen in the area of female contraception with little to offer for the male. The most likely new technology strategies to reach practical application in the next decade are steroid implants, new injectables, better IUCDs, vaginal rings, prostaglandins for abortion and nonsteroidal anti-ovulation agents. The fate of radically superior new methods such as contraceptive vaccines, menses-inducing pills or tampons, and pills or injections for the male is uncertain at present.

All health professionals who are concerned with the control of human reproduction would do well to read Birth Control Technologies. It is scientifically impeccable and, at the same time, eminently readable. In some senses, however, it is depressing. Our contraceptive armoury has progressed little beyond modification of steroidal methods, medicated IUCDs and mechanically simplified contraception. The promise of the future is uncertain, but insofar as advances in science are predictable $\mathrm{Dr}$ Harper has given us a blueprint for the next two decades and possibly beyond.

Warren R. Jones is Professor in the Department of Obstetrics and Gynaecology at Flinders University of South Australia. 